\title{
Quality of life reported by survivors after hospitalization for Middle East respiratory syndrome (MERS)
}

\author{
Sarah Batawi ${ }^{1}$, Nehal Tarazan², Rajaa Al-Raddadi ${ }^{3}$,Eman Al Qasim ${ }^{4}$, Anees Sindi', Sameera AL Johni ${ }^{5}$, \\ Fahad M. Al-Hameed ${ }^{6}$, Yaseen M. Arabi ${ }^{6}$, Timothy M. Uyeki ${ }^{7}$ and Basem M. Alraddadi ${ }^{8^{*}}$ (1)
}

\begin{abstract}
Introduction: Data are lacking on impact of Middle East Respiratory Syndrome (MERS) on health-related quality of life (HRQoL) among survivors.

Methods: We conducted a cross-sectional survey of MERS survivors who required hospitalization in Saudi Arabia during 2016-2017, approximately 1 year after diagnosis. The Short-Form General Health Survey 36 (SF-36) was administered by telephone interview to assess 8 quality of life domains for MERS survivors and a sample of survivors of severe acute respiratory infection (SARI) without MERS. We compared mean SF-36 scores of MERS and non-MERS SARI survivors using independent t-test, and compared categorical variables using chi-square test. Adjusted analyses were performed using multiple linear regression.

Results: Of 355 MERS survivors, 83 were eligible and 78 agreed to participate. MERS survivors were younger than non-MERS SARI survivors (mean \pm SD): (44.9 years \pm 12.9 ) vs $(50.0$ years \pm 13.6$), p=0.031$. Intensive care unit (ICU) admissions were similar for MERS and non-MERS SARI survivors (46.2\% vs. 57.1\%), $p=0.20$. After adjusting for potential confounders, there were no significant differences between MERS and non-MERS SARI survivors in physical component or mental component summary scores. MERS ICU survivors scored lower than MERS survivors not admitted to an ICU for physical function $(p=0.05)$, general health $(p=0.01)$, vitality $(p=0.03)$, emotional role $(p=0.03)$ and physical component summary $(p<0.02)$.

Conclusions: Functional scores were similar for MERS and non-MERS SARI survivors. However, MERS survivors of critical illness reported lower quality of life than survivors of less severe illness. Efforts are needed to address the long-term medical and psychological needs of MERS survivors.
\end{abstract}

Keywords: Health-related quality of life (HRQoL), Coronavirus, Middle East respiratory syndrome (MERS), Pneumonia, Saudi Arabia, Severe acute respiratory infection (SARI), Long term outcome, survivors

\section{Introduction}

Middle East Respiratory Syndrome (MERS) caused by a novel coronavirus (MERS-CoV) was first identified in Saudi Arabia in 2012 [1]. Since then, MERS outbreaks have occurred in several hospitals [2, 3]. As of March 31, 2019, 2399 laboratory-confirmed MERS cases, including 827 deaths (34.5\%) worldwide have been

\footnotetext{
* Correspondence: balraddadi@kfshrc.edu.sa

${ }^{8}$ Department of Medicine, King Faisal Specialist Hospital and Research Center, University of Jeddah, P.O BOX 40047 Jeddah 21499 MBC J 46, Jeddah, Saudi Arabia

Full list of author information is available at the end of the article
}

reported to the World Health Organization (WHO [4]. The clinical presentation of MERS is variable, ranging from asymptomatic infection to critical illness and multiorgan failure requiring intensive care unit (ICU) admission for mechanical ventilation, renal replacement therapy, and vasopressor support for refractory shock [5-8]. A recent post-mortem study reported detection of MERS$\mathrm{CoV}$ by transmission electron microscopy in the lungs, kidney, and muscle of a fatal case [9]. Lung pathology of a previous fatal case of MERS demonstrated diffuse alveolar damage without evidence of extrapulmonary spread [10]. MERS-CoV infection triggers specific CD4 and CD8 T-

(c) The Author(s). 2019 Open Access This article is distributed under the terms of the Creative Commons Attribution 4.0 International License (http://creativecommons.org/licenses/by/4.0/), which permits unrestricted use, distribution, and 
cell responses that may last up to 18-34 months following the primary infection $[11,12]$. MERS severity and recovery has been correlated with CD4 T-cell response, levels of antibody and longevity, but not CD8 T-cell responses [11-15].

Patients who survived severe acute respiratory infection (SARI) due to non-MERS etiologies have reported persistent abnormalities during prospective follow up [16]. A longitudinal 2-year follow-up of survivors of severe illness from avian influenza $\mathrm{A}(\mathrm{H} 7 \mathrm{~N} 9)$ virus infection reported residual impairment in ventilation and diffusion capacity for carbon monoxide (DLCO) in more than half despite significant improvement from baseline during the first 6 months [17]. Survivors of a closely related coronavirus infection, Severe Acute Respiratory Syndrome (SARS), had residual abnormalities detected with pulmonary function testing, with impairment in DLCO up to 2 years after recovery [18]. In addition to air space changes reported in chest radiographs, further pulmonary abnormalities were observed using high resolution computed tomography [19] and impairment in Health-related quality of life (HRQoL) was also reported in SARS survivors [18].

While the clinical course and the immunological response to MERS-CoV infection have been described, data are lacking on the impact of MERS on quality of life among survivors. We aimed to describe the long-term outcomes and quality of life among survivors of MERS who required hospitalization. In addition, we compared reported HRQoL scores between MERS patients who had severe disease and those with mild disease.

\section{Methods}

\section{Study design and setting}

During February 1, 2016 to February 14, 2017, we aimed to evaluate MERS patients reported to the Ministry of Health (MOH) of Saudi Arabia from September 2014 until November 16, 2015 and who survived. Eligible patients met the following criteria: 1 ) had laboratory confirmed MERS [MERS-CoV RNA was detected in upper or lower respiratory tract specimens by real-time reverse transcription polymerase chain reaction (rRT-PCR)] [20]; 2) aged $\geq 18$ years; 3 ) were hospitalized for MERS; 4) survived for at least 1 year from the time of MERS diagnosis; and 5) had contact information available to the MOH. A sample of SARI patients who tested negative for MERS-CoV RNA in upper or lower respiratory tract specimens by rRT-PCR (non-MERS SARI) was selected to serve as a comparative cohort. We identified potential non-MERS-SARI controls randomly from retrospective records, based on the WHO case definition of SARI; 1) Any acute respiratory infection requires hospitalization with history of fever or measured temperature $\geq 38^{\circ} \mathrm{C}$;2) cough; 3) onset within the last
10 days [21]; and 4 ) aged $\geq 18$ years. Disease severity was stratified based on requirements of admission to an intensive care unit or medical ward.

We excluded 1) subjects with incomplete information on quality of life survey and 2) patients who were not able to complete the interview. Non-MERS SARI cases were selected only from one hospital; whereas the MERS cases were from multiple hospitals in Saudi Arabia.

Contact information and the data registry of MERS$\mathrm{CoV}$ patients were provided by the $\mathrm{MOH}$ in Saudi Arabia and the Ministry of National Guard Health Affairs Hospitals (Jeddah and Riyadh) and a short form health survey was administered through telephone interview by a general physician. Verbal informed consent was obtained from all participants.

\section{Short form health survey (SF-36)}

The SF- 36 is an internationally recognized instrument that has been used in clinical trials to assess the quality of life for patients with other respiratory infections, including those caused by avian influenza $\mathrm{A}(\mathrm{H} 7 \mathrm{~N} 9)$ virus (17), influenza $A(\mathrm{H} 1 \mathrm{~N} 1) p d m 09$ virus [22], and SARS$\mathrm{CoV}$ [18]. The SF-36 consists of 36 question that evaluates eight health domains: physical functioning (PF), social functioning (SF), role limitation due to physical problems (RP), role limitation due to emotional problems (RE), mental health $(\mathrm{MH})$, bodily pain $(\mathrm{BP})$, vitality (VT), and general health (GH) $[23,24]$. These domains can be further represented as physical (PSC) and mental (MCS) component summary scales. Scores for each domain can range from 0 (worst) to 100 (best) with higher scores indicating better HRQoL [24]. The Arabic version of SF-36 has been validated in the Saudi Arabian population, and no significant mean differences between Arabic and English SF-36 questionnaires were observed [25]. Patients were interviewed using the English or Arabic version as needed of the Short-Form 36-item survey (SF-36) to assess the HRQoL.

\section{Statistical analysis}

Categorical data were expressed as frequencies and percentages, continuous data were reported as means \pm SD for normally distributed data and medians and interquartile range (IQR) for non-normally distributed data. For comparisons of mean SF-36 scores between MERS and non-MERS SARI survivors, we used the independent $\mathrm{t}$-test. Categorical variables were compared using the chi-square test. Multiple linear regression was used to adjust for the following potential confounders: Age, gender, ICU admission, healthcare worker, mean time of diagnosis to interview, presence of at least one comorbidity; and immunocompromised status.

We included age and gender as covariates since these factors have been shown to affect the HRQoL [26, 27]. 
Other covariates were included because these variables were significantly different $(p<0.05)$ between MERS vs non-MERS SARI patients. Analyses were performed using SPSS. $P$-values of $<0.05$ were considered statistically significant.

\section{Ethics statement}

Institutional Review Board approval was obtained from the Ministry of Health and the Ministry of National Guard Health Affairs of Saudi Arabia.

\section{Results}

\section{Baseline characteristics of MERS and non-MERS SARI survivors}

Throughout the recruitment period from February 1, 2016 to February 142,017, 83 MERS survivors were determined to be eligible and 78 agreed to participate and were included in the final analysis (Fig. 1a). Eligible patients were interviewed from four major cities in the Kingdom: Riyadh 64 (82\%), Jeddah 9 (12\%), Ahsa 4 (5\%) and Taif 1 (1\%). Fifty-seven non-MERS SARI survivors met our inclusion criteria and were included in the analysis. MERS survivors were younger when compared to non-MERS SARI survivors (mean $\pm \mathrm{SD}$ ): (44.9 years \pm 12.9 ) vs (50.0 years \pm 13.6 ), $p=0.031$. The mean time from illness onset to interview was significantly longer in the non-MERS SARI cases than MERS survivors, mean $( \pm$ SD), 25.3 months (7.5) and 13.8 months (3.4) respectively $(p<0.01)$. Twenty $(25.6 \%)$ MERS survivors were healthcare personnel, whereas only two $(3.5 \%)$ of the non-MERS survivors worked in a hospital at the time of illness onset $(\mathrm{p}<0.01)$. Non-MERS survivors were more likely than MERS survivors to report a preexisting medical condition. (Table 1).

\section{Main outcomes}

MERS survivors $(n=78)$ had significantly higher mean SF-36 scores than non-MERS SARI patients $(n=57)$ for the following domains (Table 2): physical functioning [mean \pm SD $(72.47 \pm 26.11)$ vs $(55.26 \pm 35.07), \mathrm{p}<0.01$ ], physical role [(64.87 \pm 39.12$)$ vs $(50.00 \pm 42.52), p=0.04]$, general health $[(73.03 \pm 22.68)$ vs $(63.95 \pm 23.52), p=$ 0.03 ], vitality [( $65.96 \pm 26.47)$ vs $(53.60 \pm 28.80), p=0.01$ ] and physical component summary $(71.33 \pm 22.20)$ vs (59.77 \pm 27.00$), p=0.01]$. After adjusting for potential confounders, there were no significant differences between the physical or mental component summary scores between the two groups At the time of the survey, the majority of MERS survivors (88\%) had returned to their original work compared with $74 \%$ of non-MERS SARI survivors, $p=0.17$.

Mean SF-36 scores reported among MERS survivors stratified by disease severity are summarized in Table 3 . SF-36 domain scores for those admitted to an intensive care unit $(n=36)$ were significantly lower than survivors managed in medical wards $(n=42)$ in the following domains, physical functioning [mean \pm SD $(66.94 \pm 30.29)$ vs $(78.69 \pm 18.78), p<0.05]$, general health $[(65.94 \pm$ $26.97)$ vs $(79.10 \pm 16.21), p=0.01]$, vitality $[(58.47 \pm$ $31.60)$ vs $(72.38 \pm 19.29), \quad p=0.03]$, emotional role $[(65.74 \pm 38.62)$ vs $(83.33 \pm 33.13), p=0.03]$, and physical component summary $[(64.84 \pm 25.52)$ vs $(76.90 \pm 17.35)$, $p=0.02$ ] (Table 3). After adjustment for potential confounders, MERS ICU survivors had a significantly lower

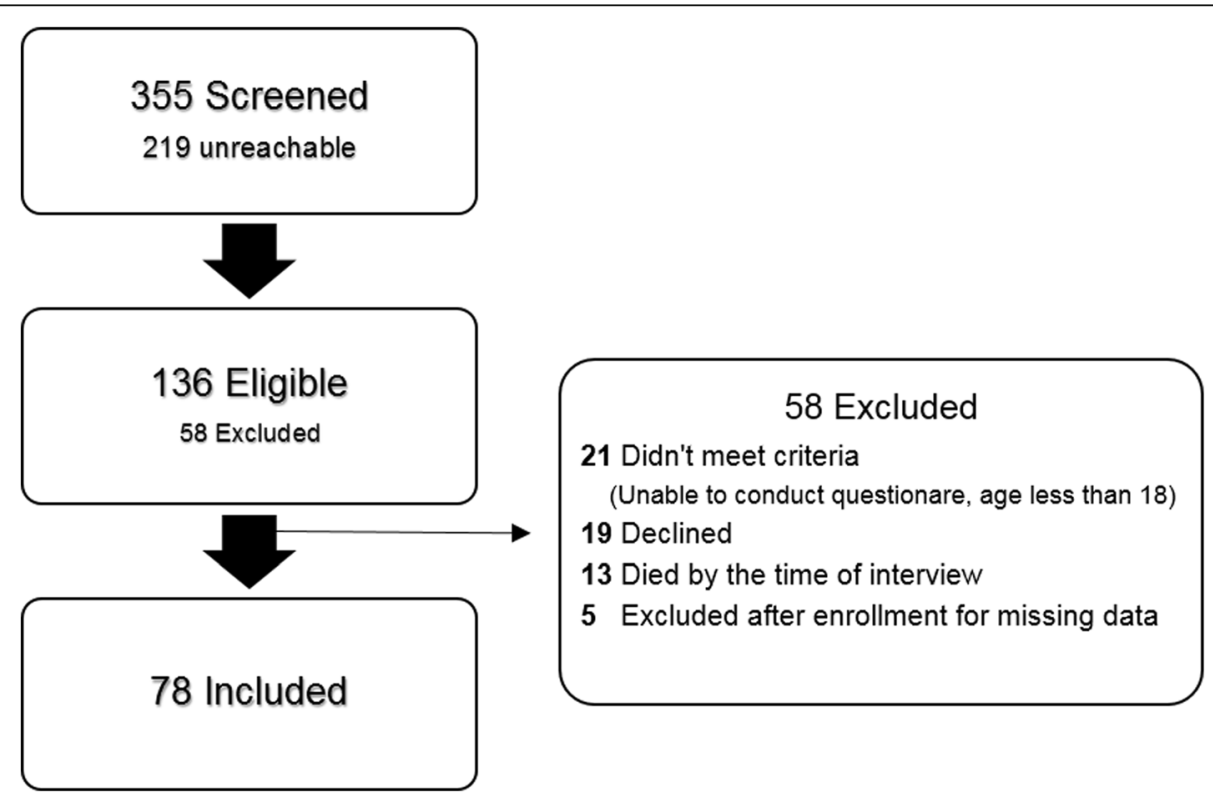

Fig. 1 a MERS survivor recruitment process 
Table 1 Baseline Characteristics of patients with Middle East Respiratory Syndrome (MERS) and patients with Non-MERS Severe Acute Respiratory Infection (SARI) at the time of diagnosis

\begin{tabular}{|c|c|c|c|}
\hline Characteristic & MERS $N=78(\%)$ & Non-MERS SARI N = 57 (\%) & $p$-value \\
\hline Age-years (Mean \pm SD) & $(44.99 \pm 12.95)$ & $(50.04 \pm 13.64)$ & 0.31 \\
\hline Male gender & $56(71.8 \%)$ & $34(59.6 \%)$ & 0.14 \\
\hline Nationality-Saudi & $56(71.8 \%)$ & $34(59.6 \%)$ & 0.14 \\
\hline ICU admission & $36(46.2 \%)$ & $32(57.1 \%)$ & 0.20 \\
\hline Mechanically ventilated & $26(33.3 \%)^{c}$ & $26(45.6 \%)$ & 0.10 \\
\hline Health care worker & $20(25.6 \%)$ & $2(3.5 \%)$ & $<0.01$ \\
\hline Presence of comorbidity (one or more) & $45(63.4 \%)$ & $44(91.7 \%)$ & $<0.01$ \\
\hline \multicolumn{4}{|l|}{ Comorbidities } \\
\hline Diabetes & $29(37.2 \%)$ & $28(50.9 \%)$ & 0.12 \\
\hline Hypertension & $29(37.2 \%)$ & $29(51.8 \%)$ & 0.09 \\
\hline Respiratory disease & $2(2.6 \%)$ & 0 & 0.33 \\
\hline Cardiovascular disease & $10(12.8 \%)$ & 19 (33.9\%) & $<0.01$ \\
\hline Neurological disease & $4(5.1 \%)$ & $12(21.4 \%)$ & $<0.01$ \\
\hline Renal disease & $9(11.5 \%)$ & $15(26.8 \%)$ & 0.02 \\
\hline Hemodialysis & $3(3.9 \%)$ & $3(5.4 \%)$ & 0.70 \\
\hline Chronic liver disease & 0 & $7(12.5 \%)$ & $<0.01$ \\
\hline Immunocompromised ${ }^{\mathrm{a}}$ & $6(7.7 \%)$ & $20(35.7 \%)$ & $<0.01$ \\
\hline Current smoker or history of smoking & $26(33.3 \%)$ & $11(19.6 \%)$ & 0.08 \\
\hline Time to interview after illness -month (Mean \pm SD) & $(13.79 \pm 3.43)$ & $(25.32 \pm 7.54)$ & $<0.01$ \\
\hline Returned to original work at the time of interview & $44(88 \%)^{b}$ & $17(73.9 \%)$ & 0.17 \\
\hline
\end{tabular}

Immunocompromised patients were defined as follows: (Use of systemic corticosteroids or immunosuppressive medication, preexisting organ transplantation and active cancer)

${ }^{b}$ Subjects who were originally not working were excluded in the analysis

'Percentage from total patients with MERS (78) and Non-MERS SARI (57)

mental component summary score than MERS survivors cared for on medical wards $(p<0.026)$, but no significant difference was found in physical component summary score.

\section{Discussion}

In this study, the overall quality of life reported by MERS survivors at approximately 14 months of follow- up was lower than that reported by non-MERS SARI survivors, although the difference became insignificant when adjusted for relevant confounders. In addition, survivors who required intensive care unit admission reported significantly lower overall quality of life than MERS survivors with less severe illness who were hospitalized in general medical wards. MERS survivors also reported significantly lower quality physical health at

Table 2 Average score of SF36 components reported by MERS survivors $(n=78)$ and non-MERS SARI survivors $(n=57)$

\begin{tabular}{llll}
\hline SF36 component & MERS $(n=78)$ mean (SD) & Non-MERS SARI survivors $(n=57)$ mean (SD) & $p$-value \\
\hline Physical functioning & $72.47(26.11)$ & $55.26(35.07)$ & $<0.01$ \\
Physical role & $64.87(39.12)$ & $50.00(42.52)$ & 0.04 \\
Pain & $78.97(29.84)$ & $76.05(33.88)$ & 0.60 \\
General health & $73.03(22.68)$ & $63.95(23.52)$ & 0.03 \\
Vitality & $65.96(26.47)$ & $53.60(28.80)$ & 0.01 \\
Social functioning & $84.45(24.36)$ & $75.44(32.04)$ & 0.08 \\
Emotional role & $75.12(36.39)$ & $62.58(42.76)$ & 0.08 \\
Mental health & $79.64(22.34)$ & $74.74(24.03)$ & 0.23 \\
Physical component Summary & $71.33(22.20)$ & $59.77(27.00)$ & 0.01 \\
Mental component Summary & $79.77(23.20)$ & $70.92(28.53)$ & 0.06 \\
\hline
\end{tabular}


Table 3 Average score of SF36 components reported by MERS-CoV survivors admitted to an ICU ( $n=36$ ) or a medical ward (non ICU) $(n=42)$

\begin{tabular}{llll}
\hline & MERS ICU $(n=36)$ mean (SD) & MERS Non ICU $(n=42)$ mean (SD) & $P$ value \\
\hline Physical functioning & $66.94(30.29)$ & $78.69(18.78)$ & 0.05 \\
Physical role & $58.33(40.53)$ & $72.02(36.29)$ & 0.12 \\
Pain & $74.51(33.55)$ & $82.29(26.34)$ & 0.27 \\
General health & $65.94(26.97)$ & $79.10(16.21)$ & 0.01 \\
Vitality & $58.47(31.60)$ & $72.38(19.29)$ & 0.03 \\
Social functioning & $81.60(28.74)$ & $86.89(19.90)$ & 0.36 \\
Emotional role & $65.74(38.62)$ & $83.33(33.13)$ & 0.03 \\
Mental health & $77.11(24.46)$ & $81.81(20.40)$ & 0.36 \\
Physical component Summary & $64.84(25.52)$ & $76.90(17.35)$ & 0.02 \\
Mental component Summary & $74.82(25.14)$ & $84.01(20.77)$ & 0.09 \\
\hline
\end{tabular}

Continuous data were compared using independent t-test

approximately 14 months after illness onset compared to a previously published sample of healthy individuals in Saudi Arabia.

Our findings are similar to those reported in studies of long-term follow-up of survivors of SARI due to other etiologies associated with high mortality. The overall scores of SF-36 domains (with exception for mental health and role emotion) were significantly lower in survivors of SARS-CoV at 2 years compared with the general Hong Kong population [18]. Similar findings were observed at 1-year follow-up evaluation among patients who survived critical illness and the acute respiratory distress syndrome from influenza $\mathrm{A}(\mathrm{H} 1 \mathrm{~N} 1) \mathrm{pdm} 09$ virus infection compared with a sample of the general population [22]. In a recent study that assessed survivors of severe disease due to avian influenza $\mathrm{A}(\mathrm{H} 7 \mathrm{~N} 9)$ virus infection in China, quality of life reported at approximately 1.5 years was lower than a sample of the general population [17].

Longitudinal studies have documented some improvements in quality of life reported over time [28]. However, the changes are not uniformly distributed across the SF36 components. In SARS-CoV survivors, the qualityof-life scores for the following domains (social functioning, role physical and role emotional) were lowest at discharge, increased substantially at 1 year [29], and remained stable at 2 years [18]. In another SARS-CoV survivor study, there was a significant improvements in role physical, social function, and role emotional domains at one-year evaluation [16, 17]. However, a study of survivors who were hospitalized with avian influenza $\mathrm{A}(\mathrm{H} 7 \mathrm{~N} 9)$ virus infection did not find any significant changes in reported SF-36 domains from 3 to 24 months post-discharge follow-up [17].

MERS survivors had a similar degree of impairment identified on HRQoL compared to SARI survivors of non-MERS-CoV origin. Despite the longer interval in the assessments in non-MERS SARI survivors, reported quality of life scores were similar after adjustments of potential confounders using a linear regression model. Due to the descriptive cross-sectional study design, any temporal relationship may be undetected; MERS could have a transient effect on survivors at discharge, and it is possible we were unable to detect these dynamic changes. Corticosteroid-induced myopathy, muscle wasting and weakness have been reported in survivors of ARDS at one-year follow up [30]. Since many MERS ICU patients have been treated with high-dose corticosteroids, sequelae from such therapy could contribute to reduced quality of life in survivors. Additionally, critically ill MERS survivors had impairment in the emotional role that might be attributed to psychological trauma similar to that observed in survivors of the 2003 SARS outbreak [31].

Our study is subject to several limitations. First, selection bias may be present; as the small study population may not be representative of all eligible Saudi MERS survivors -since the majority of survivors were unreachableand our non-MERS SARI controls were enrolled from only two hospitals in Saudi Arabia. Additionally, the number of non-MERS SARI controls was lower than MERS survivors. Second, we had limited medical information on potential predictors that may alter the reported quality of life scores. Specifically, we did not have information regarding the severity of illness such as APACHE II score, number of ventilator days, length of hospital stay, or use of sedatives or neuromuscular blocking agents which have been shown to affect long term outcomes. Third, there is a potential for recall bias since there was a significant difference in time from illness onset to interview time between MERS cases and non-MERS SARI controls; to reduce bias, we performed a multiple linear regression model to adjust for confounders. Lastly, we administered the SF-36 questionnaire by telephone 
and not in-person. However, telephone administration has been validated in previous studies and shown to be a reliable method when compared to a selfadministered survey [32, 33].

This cross-sectional observational study has provided preliminary information about the quality of life of MERS survivors. Assessment of functional limitation and exercise capacity is needed in MERS survivors to estimate the long-term burden of this illness. Prospective longitudinal studies measuring objective parameters such as; pulmonary function testing, 6-min walk test and detection of depression, anxiety and post-traumatic stress disorder with correlation with health status, will provide more informative data to understanding of the overall long term outcomes of MERS-CoV infection.

\section{Conclusions}

Approximately 14 months after onset of MERS illness, ICU survivors reported higher limitations in some measure of their quality of life than patients with less severe illness who were managed in medical wards. The longterm consequences of MERS illness on survivors may be similar to that caused by SARI of other etiologies. Further attention is needed to address the long-term medical and psychological needs of survivors of MERS and non-MERS SARI.

\section{Abbreviations \\ BP: Bodily pain; DLCO: Diffusion capacity for carbon monoxide; GH: General health; HRQoL: Health-related quality of life; ICU: Intensive care unit; IQR: Interquartile range; MCS: Mental component summary scales; MERS: Middle East Respiratory Syndrome; MERS-CoV: Middle East Respiratory Syndrome coronavirus; $\mathrm{MH}$ : Mental health; $\mathrm{MOH}$ : Ministry of Health; PF: Physical functioning; PSC: Physical component summary scales; RE: Role limitation due to emotional problems; RP: Role limitation due to physical problems; rRT-PCR: Real-time reverse transcription polymerase chain reaction; SF: Social functioning; SF-36: The Short-Form General Health Survey 36; VT: Vitality (VT)}

\section{Acknowledgements}

Not applicable.

\section{Authors'contributions}

SB Conception and design, data acquisition, analytical plan, interpretation of data for the work, drafting of the manuscript, critical revision of the manuscript for important intellectual content, approval of the final version to be published and agreement to be accountable for all aspects of the work. NT Conception and design, data acquisition, analytical plan, interpretation of data for the work, drafting of the manuscript, critical revision of the manuscript for important intellectual content, approval of the final version to be published and agreement to be accountable for all aspects of the work. RA analytical plan, interpretation of data for the work, drafting of the manuscript, critical revision of the manuscript for important intellectual content approval of the final version to be published and agreement to be accountable for all aspects of the work. EA data acquisition, interpretation of data for the work, drafting of the manuscript, critical revision of the manuscript for important intellectual content, approval of the final version to be published and agreement to be accountable for all aspects of the work. SA data acquisition, interpretation of data for the work, drafting of the manuscript, critical revision of the manuscript for important intellectual content, approval of the final version to be published and agreement to be accountable for all aspects of the work. FA data acquisition, interpretation of data for the work, drafting of the manuscript, critical revision of the manuscript for important intellectual content, approval of the final version to be published and agreement to be accountable for all aspects of the work. YA Conception and design, data acquisition, analytical plan, interpretation of data for the work, drafting of the manuscript, critical revision of the manuscript for important intellectual content, approval of the final version to be published and agreement to be accountable for all aspects of the work. TU Conception and design, analytical plan, interpretation of data for the work, drafting of the manuscript, critical revision of the manuscript for important intellectual content, approval of the final version to be published and agreement to be accountable for all aspects of the work. BA Conception and design, data acquisition, analytical plan, interpretation of data for the work, drafting of the manuscript, critical revision of the manuscript for important intellectual content, approval of the final version to be published and agreement to be accountable for all aspects of the work. AS data acquisition, interpretation of data for the work, drafting of the manuscript, critical revision of the manuscript for important intellectual content, approval of the final version to be published and agreement to be accountable for all aspects of the work.

\section{Disclaimer}

The findings and conclusions in this report are those of the authors and do not necessarily represent the official position of the U.S. Centers for Disease Control and Prevention.

\section{Funding}

None.

Availability of data and materials

The datasets used and/or analysed during the current study are available from the corresponding author on reasonable request.

\section{Ethics approval and consent to participate}

Institutional Review Board approval was obtained from the Ministry of Health and the Ministry of National Guard Health Affairs of Saudi Arabia.

\section{Consent for publication}

Not applicable.

\section{Competing interests}

The authors declare that they have no competing interests.

\section{Author details}

${ }^{1}$ King Abdulaziz University, Jeddah, Saudi Arabia. ${ }^{2}$ King Faisal Specialist Hospital and Research Center, Jeddah, Saudi Arabia. ${ }^{3}$ Department of Community Medicine, King Abdulaziz University, Jeddah, Saudi Arabia. ${ }^{4}$ King Abdullah International Medical Research Center, King Abdulaziz Medical City - National Guard Health Affairs, Riyadh, Saudi Arabia. ${ }^{5}$ King Saud Bin Abdulaziz University for Health Sciences, Riyadh, Saudi Arabia. ${ }^{6}$ King Abdullah International Medical Research Center, King Saud bin Abdulaziz University for Health Sciences, Intensive Care Department, King Abdulaziz Medical City National Guard Health Affairs, Jeddah, Saudi Arabia. ${ }^{7}$ Influenza Division, National Center for Immunization and Respiratory Diseases, Centers for Disease Control and Prevention, Atlanta, Georgia, USA. ${ }^{8}$ Department of Medicine, King Faisal Specialist Hospital and Research Center, University of Jeddah, P.O BOX 40047 Jeddah 21499 MBC J 46, Jeddah, Saudi Arabia.

Received: 12 February 2019 Accepted: 23 May 2019

Published online: 11 June 2019

\section{References}

1. Zaki AM, van Boheemen S, Bestebroer TM, Osterhaus AD, Fouchier RA Isolation of a novel coronavirus from a man with pneumonia in Saudi Arabia. N Engl J Med. 2012;367(19):1814-20.

2. Oboho IK, Tomczyk SM, Al-Asmari AM, Banjar AA, Al-Mugti H, Aloraini MS, Alkhaldi KZ, Almohammadi EL, Alraddadi BM, Gerber SI, et al. 2014 MERSCoV outbreak in Jeddah--a link to health care facilities. N Engl J Med. 2015; 372(9):846-54

3. Balkhy $H H$, Alenazi TH, Alshamrani MM, Baffoe-Bonnie $H$, Arabi $Y$, Hijazi R, Al-Abdely HM, El-Saed A, Al Johani S, Assiri AM, et al. Description of a hospital outbreak of Middle East respiratory syndrome in a large 
tertiary Care Hospital in Saudi Arabia. Infect Control Hosp Epidemiol. 2016;37(10):1147-55.

4. Update WHOMErscM-CTKoSADON, 24 April 2019. Accessed on May 6 ahwwicd-A--m-s-ae.

5. Assiri A, Al-Tawfiq JA, Al-Rabeeah AA, Al-Rabiah FA, Al-Hajjar S, Al-Barrak A, Flemban H, Al-Nassir WN, Balkhy HH, Al-Hakeem RF, et al. Epidemiological, demographic, and clinical characteristics of 47 cases of Middle East respiratory syndrome coronavirus disease from Saudi Arabia: a descriptive study. Lancet Infect Dis. 2013;13(9):752-61.

6. Arabi YM, Arifi AA, Balkhy HH, Najm H, Aldawood AS, Ghabashi A, Hawa H, Alothman A, Khaldi A, Al Raiy B. Clinical course and outcomes of critically ill patients with Middle East respiratory syndrome coronavirus infection. Ann Intern Med. 2014;160(6):389-97.

7. Arabi YM, Balkhy HH, Hayden FG, Bouchama A, Luke T, Baillie JK, Al-Omari A, Hajeer AH, Senga M, Denison MR, et al. Middle East respiratory syndrome. N Engl J Med. 2017;376(6):584-94.

8. Arabi YM, Al-Omari A, Mandourah Y, Al-Hameed F, Sindi AA, Alraddadi B, Shalhoub S, Almotairi A, Al Khatib K, Abdulmomen A, et al. Critically ill patients with the Middle East respiratory syndrome: a multicenter retrospective cohort study. Crit Care Med. 2017;45(10):1683-95.

9. Alsaad KO, Hajeer AH, Al Balwi M, Al Moaiqel M, Al Oudah N, Al Ajlan A, AlJohani S, Alsolamy S, Gmati GE, Balkhy H, et al. Histopathology of Middle East respiratory syndrome coronovirus (MERS-CoV) infection - clinicopathological and ultrastructural study. Histopathology. 2018;72(3):516-24.

10. Ng DL, Al Hosani F, Keating MK, Gerber Sl, Jones TL, Metcalfe MG, Tong S, Tao Y, Alami NN, Haynes LM, et al. Clinicopathologic, Immunohistochemical, and ultrastructural findings of a fatal case of Middle East respiratory syndrome coronavirus infection in the United Arab Emirates, April 2014. Am J Pathol. 2016;186(3):652-8.

11. Alshukairi AN, Khalid I, Ahmed WA, Dada AM, Bayumi DT, Malic LS, Althawadi S, Ignacio K, Alsalmi HS, Al-Abdely HM, et al. Antibody response and disease severity in healthcare worker MERS survivors. Emerg Infect Dis. 2016;22(6). www.cdc.gov/eid.

12. Payne DC, Iblan I, Rha B, Alqasrawi S, Haddadin A, Al Nsour M, Alsanouri T, Ali SS, Harcourt J, Miao C, et al. Persistence of antibodies against Middle East respiratory syndrome coronavirus. Emerg Infect Dis. 2016;22(10):1824-6.

13. Zhao J, Alshukairi AN, Baharoon SA, Ahmed WA, Bokhari AA, Nehdi AM, Layqah LA, Alghamdi MG, Al Gethamy MM, Dada AM, et al. Recovery from the Middle East respiratory syndrome is associated with antibody and T-cell responses. Sci Immunol. 2017;2(14). https://doi.org/10.1126/sciimmunol. aan5393.

14. Choe PG, Perera R, Park WB, Song KH, Bang JH, Kim ES, Kim HB, Ko LWR, Park SW, Kim NJ, et al. MERS-CoV antibody responses 1 year after symptom onset, South Korea, 2015. Emerg Infect Dis. 2017;23(7):1079-84.

15. Ko JH, Muller MA, Seok H, Park GE, Lee JY, Cho SY, Ha YE, Baek JY, Kim SH, Kang JM, et al. Serologic responses of 42 MERS-coronavirus-infected patients according to the disease severity. Diagn Microbiol Infect Dis. 2017; 89(2):106-11.

16. Tansey CM, Louie M, Loeb M, Gold WL, Muller MP, de Jager J, Cameron Jl, Tomlinson G, Mazzulli T, Walmsley SL, et al. One-year outcomes and health care utilization in survivors of severe acute respiratory syndrome. Arch Intern Med. 2007;167(12):1312-20.

17. Chen J, Wu J, Hao S, Yang M, Lu X, Chen X, Li L. Long term outcomes in survivors of epidemic influenza a (H7N9) virus infection. Sci Rep. 2017;7(1): 17275.

18. Ngai JC, Ko FW, Ng SS, To KW, Tong M, Hui DS. The long-term impact of severe acute respiratory syndrome on pulmonary function, exercise capacity and health status. Respirology. 2010;15(3):543-50.

19. Ng CK, Chan JW, Kwan TL, To TS, Chan YH, Ng FY, Mok TY. Six month radiological and physiological outcomes in severe acute respiratory syndrome (SARS) survivors. Thorax. 2004;59(10):889-91.

20. Madani TA, Althaqafi AO, Alraddadi BM. Infection prevention and control guidelines for patients with Middle East respiratory syndrome coronavirus (MERS-CoV) infection. Saudi Med J. 2014;35(8):897-913.

21. WHO surveillance case definitions for ILI and SARI https://www.who.int/ influenza/surveillance_monitoring/ili_sari_surveillance_case_definition/en/. Accessed 31 May 2019.

22. Luyt $C E$, Combes $A$, Becquemin MH, Beigelman-Aubry $C$, Hatem $S$, Brun $A L$, Zraik N, Carrat F, Grenier PA, Richard JM, et al. Long-term outcomes of pandemic 2009 influenza a(H1N1)-associated severe ARDS. Chest. 2012; 142(3):583-92.
23. McHorney CA, Ware JE Jr, Lu JF, Sherbourne CD. The MOS 36-item shortform health survey (SF-36): III. Tests of data quality, scaling assumptions, and reliability across diverse patient groups. Med Care. 1994;32(1):40-66.

24. Ware JE Jr, Sherbourne CD. The MOS 36-item short-form health survey (SF-36). I. Conceptual framework and item selection. Med Care. 1992; 30(6):473-83.

25. Coons SJ, Alabdulmohsin SA, Draugalis JR, Hays RD. Reliability of an Arabic version of the RAND-36 health survey and its equivalence to the US-English version. Med Care. 1998;36(3):428-32.

26. Campos AC, Ferreira e Ferreira E, Vargas AM, Albala C. Aging, gender and quality of life (AGEQOL) study: factors associated with good quality of life in older Brazilian community-dwelling adults. Health Qual Life Outcomes. 2014;12:166.

27. Liu H, Feurer ID, Dwyer K, Speroff T, Shaffer D, Wright Pinson C. The effects of gender and age on health-related quality of life following kidney transplantation. J Clin Nurs. 2008;17(1):82-9.

28. Dowdy DW, Eid MP, Sedrakyan A, Mendez-Tellez PA, Pronovost PJ, Herridge MS, Needham DM. Quality of life in adult survivors of critical illness: a systematic review of the literature. Intensive Care Med. 2005;31(5):611-20.

29. Hui DS, Wong KT, Ko FW, Tam LS, Chan DP, Woo J, Sung JJ. The 1-year impact of severe acute respiratory syndrome on pulmonary function, exercise capacity, and quality of life in a cohort of survivors. Chest. 2005; 128(4):2247-61.

30. Herridge MS, Cheung AM, Tansey CM, Matte-Martyn A, Diaz-Granados N, AlSaidi F, Cooper AB, Guest CB, Mazer CD, Mehta S, et al. One-year outcomes in survivors of the acute respiratory distress syndrome. N Engl J Med. 2003; 348(8):683-93.

31. Lee AM, Wong JG, McAlonan GM, Cheung V, Cheung C, Sham PC, Chu CM, Wong PC, Tsang KW, Chua SE. Stress and psychological distress among SARS survivors 1 year after the outbreak. Can J Psychiatry. 2007;52(4):233-40.

32. Watson EK, Firman DW, Baade PD, Ring I. Telephone administration of the SF-36 health survey: validation studies and population norms for adults in Queensland. Aust N Z J Public Health. 1996;20(4):359-63.

33. Garcia M, Rohlfs I, Vila J, Sala J, Pena A, Masia R, Marrugat J. Comparison between telephone and self-administration of short form health survey questionnaire (SF-36). Gac Sanit. 2005;19(6):433-9.

\section{Publisher's Note}

Springer Nature remains neutral with regard to jurisdictional claims in published maps and institutional affiliations.

Ready to submit your research? Choose BMC and benefit from:

- fast, convenient online submission

- thorough peer review by experienced researchers in your field

- rapid publication on acceptance

- support for research data, including large and complex data types

- gold Open Access which fosters wider collaboration and increased citations

- maximum visibility for your research: over $100 \mathrm{M}$ website views per year

At $\mathrm{BMC}$, research is always in progress.

Learn more biomedcentral.com/submissions 